\title{
EFFECT OF L-CARNITINE ON THE LINGUAL MUCOSA OF STREPTOZOTOCIN-INDUCED DIABETIC ALBINO RATS
}

\author{
Laila E Amin", Mohamed A Abou El Enin** and Sally H Abou Baker***
}

\begin{abstract}
Background: Diabetes mellitus (DM) is a significant healthcare problem concern worldwide that has different pathological effects on the body tissues and organs. A number of oral soft tissue abnormalities have been associated with DM by various reports. L-carnitine (LC) is an essential nutrient that is present in almost all animal species, microorganisms and plants.The scope of this study is two-fold: 1) to investigate degenerative changes in the epithelium of the diabetic rat tongue, and 2) to test the hypothesis that (LC) attenuates epithelial cell degeneration.
\end{abstract}

Materials and methods: Thirty adult male albino rats were divided into 3 equal groups: group I; (control group), group II; (diabetic group): diabetes was induced by a single intraperitoneal injection of streptozotocin in a dose of $35 \mathrm{mg} / \mathrm{kg}$ and group III; (LC) rats were treated as in diabetic group and injected intraperitoneally by (LC) at a dose of $300 \mathrm{mg} / \mathrm{kg}$ b.w/day for 4 weeks. By the end of the experimental periods all animals were sacrificed and the tongue of all rats were dissected and processed for light and immunohistochemical examinations.

Results: Examination of dorsal surface of diabetic rats' tongues revealed numerous filliform papillae with evidently disturbed orientation and inclination. Some of them appear notched; others were destructed with desquamation of its epithelial covering. Dorsal surface of rats' tongues of (LC) group revealed almost normal direction, distribution and structure of the papillae and taste buds. Immunohistochemical examination of Ki67 expression of the control group showed significant decrease in Ki67 positive immunoreactivity, indicating less proliferative changes. While (LC) treated group revealed expression of Ki67, that statistically having no significant difference with control group.

KEY WORDS: L-Carnitine-diabetes- tongue- lingual mucosa

* Oral Biology Department, Faculty of Dentistry, Mansoura University

** Physiology Department, Faculty of Medicine, Mansoura University

*** Oral Biology Department, Faculty of Dentistry, Mansoura University 


\section{INTRODUCTION}

Diabetes mellitus is a chronic disease affecting all age groups and one of the leading causes of mortality and morbidity worldwide ${ }^{1}$. The chronic hyperglycemia and attendant metabolic dysregulation in diabetes mellitus (DM) may be associated with secondary damage in multiple organ systems, especially the kidneys, eyes, nerves and blood vessels ${ }^{2}$.

The association between DM and changes in the oral cavity has been reported in both the medical and dental literatures. A number of oral soft tissue abnormalities have been associated with DM by various reports, with more emphasis being given on its relation with periodontal diseases ${ }^{3}$. There are strong evidence of both type 1 and type 2 diabetic patients having more severe periodontal disease than do individuals without diabetes ${ }^{4-8}$.

Burning mouth syndromes which particularly affects the tongue and reported in subjects with undiagnosed diabetes are not related primarily to candida infection and almost always resolves when glycemic control is instituted ${ }^{1}$.Other specific conditions that have been identified include geographic tongue, fissured tongue, median rhomboid glossitis, hyperplastic gingivitis, lichen planus, parotid gland enlargement, candidiasis, xerostomia, burning sensations of oral mucosa, taste disturbances, increased incidence and severity of dental caries, traumatic ulcers, etc ${ }^{3}$.

(LC) is an essential nutrient that is present in almost all animal species, microorganisms and plants 9 . It is involved in many different processes in the human body:energy production, membrane biosynthesis and repair, removal of toxic substrates, anti-apoptotic mechanisms, transport of fatty acids through the internal mitochondrial membrane with concomitant removal of toxic by-products of fatty acids metabolism ${ }^{10,11}$.

(LC) levels in the body are the result of exogenous uptake, endogenous synthesis and tubular reabsorption in the kidneys ${ }^{12}$. Endogenous synthesis is mainly done in the liver, the kidneys and brain from methionine and lysine ${ }^{13}$. Its concentration is increased in tissues that require high amounts of energy, like muscles and the myocardium ${ }^{14}$. This justifies the decreased (LC) plasma level, that is $0.6 \%$ of the whole body content $(21 \mathrm{gr})^{15}$. Muscle cells are not able to biosynthesize (LC), thus exogenous (LC) is essential for muscle metabolism ${ }^{16}$.Meat (especially red meat), fish, chicken, and dairy products are rich sources of $(\mathrm{LC})^{17}$.

(LC) influences carbohydrate metabolism. Aberrations in (LC) regulation are implicated in complications of diabetes mellitus, hemodialysis, trauma malnutrition, cardiomyopathy, obesity, fasting, drug interactions, endocrine imbalances and other disorders ${ }^{18}$.

The development of type 2 diabetes is accompanied by decreased immune function. It has been suggested that oxidative damage and mitochondrial dysfunction may play an important role in the immune dysfunction in diabetes.This hypothesis was tested using mitochondrial targeting nutrients in a diabetic rat model. Administration of a combination of mitochondrial targeting nutrients, including (LC), suggested (LC) may be effective in improving immune function in type 2 diabetes through enhancement of mitochondrial function, oxidative damage, and delayed cell death in the immune organs and blood ${ }^{19}$.

Ki-67 protein is a cellular marker for proliferation ${ }^{20}$. $\mathrm{Ki}-67$ protein has a critical role in cell division. This has been concluded from the arrest of cell proliferation when Ki-67 is blocked ${ }^{21}$. Ki-67 protein is detected in G1, S, G2 and M phases of cell cycle, but not in G0 ${ }^{22}$. So it is present in all dividing cells of normal and tumor tissues, but absent in resting cells ${ }^{23}$. And it is expressed only by dividing cells, it can be used as a proliferation index ${ }^{24}$.

\section{MATERIAL AND METHODS}

Thirty healthy male Sprague Dawley rats, $80 \pm 5$ days old with average weight of $250 \pm 50$ grams old were used in the study divided into 3 groups. 


\section{Experimental Groups}

Group I: control group.

Group II: diabetic group

Group III: diabetic and receive (LC)

\section{Induction of Diabetes}

Rats were fed on normal diet ad libitum , after 2 weeks, Streptozocin $(35 \mathrm{mg} / \mathrm{kg}$ ) was given intraperitoneal in the lower-right quadrant of the abdomen to groups (II, III) while the control rats instead received the normal saline ${ }^{25}$. After one week of streptozocin injection, serum glucose and insulin levels of all rats were measured by retro-orbital plexus sampling to confirm the development of T2DM in diabetic and (LC) groups

\section{L-carnitine (LC)}

L-carnitine (LC) (Carnitor, Sigma-Tau, Maryland, USA) was administered at a dose of $300 \mathrm{mg} /$ $\mathrm{kg}$ b.w./day intraperitoneallyfor 28 days to (LC) group(III, VI) ${ }^{26}$.

The Experimental protocol with designed in accordance with the guidelines for the responsible use in animals in research as a part of the scientific research ethics recommendation.

\section{Measurement of Glucose and Insulin Serum Level}

Non- fasting blood samples for glucose and insulin assays were obtained from the retro-orbital plexus. Retro-orbital blood was drawn in the morning, every week, promptly centrifuged, and serum was stored at $-80^{\circ} \mathrm{C}$ until analysis. Serum glucose concentration was measured by a glucose oxidase method, and serum insulin concentration was determined using a mouse insulin ELISA kit (Sigma - Aldrish, St louis, MO, USA).

By the end of experimental periods, animals of each group were sacrificed by exposure to light ether anesthesia. Tongues were carefully dissected and processed for light and immunohistochemical examination.

\section{Preparation of the specimen for examination by Light microscopy}

Specimen from all rats' tongue were fixed in $10 \%$ formalin saline. Paraffin blocks were prepared and5 $\mu$ sections were stained using Haematoxylin and Eosin (H\&E) stain.

Immunohistochemical analysis was performed with the avidin-biotin-peroxidase method and used monoclonal antibody: Ki-67 (Spring Bioscience, Pleasanton, California, USA). It is used to demonstrate the expression of this nuclear protein, staining the nuclei of pro-liferating cells and highlighting all cells that have entered the cell division cycle.

Cell proliferation was evaluated using the Ki67 labeling index (LI).The evaluation of the cell proliferation rate was performed using common percentage ratio. Five areas of greater intensity of immune marker expression were selected. At least 500 cells were counted, and the ratio between the number of cells that had a positively stained nucleus and the total number of cells was calculated ${ }^{27,28}$.

\section{RESULTS}

\section{H\&E stain}

Dorsal surface of the tongue of control group showed filliform papillae appeared sharp conical covered with stratified squamous epithelium with thin regular keratin layer. Well-formed connective tissue and muscle fibers running in different direction were also noticed (Figure 1, a).

Examination of the tongues of diabetic rats revealed loss of the normal appearance of filliform papillae and separation of its covering keratin. Most of them showed flattening, loss of their characteristic conical shape surround elongated fungiform papilla. Their epithelial lining showed marked thickening and ill defined CT papillae (Figures 1, b).

Dorsal surface of the tongue of (LC) group showed almost normal structure of filliform papillae including their covering epithelium and keratin . However there were some regions that showed short ill defined filliform papillae (Figure $1, \mathrm{c}$ ). 


\section{Immunohistochemical results}

Control group: the normal tongue showed only a few cells with positive nuclear reaction and some endothelial cells showed positive reaction (Figure 2, A)
Diabetic group: showed very rare immunoreaction and many slides show negative nuclear reaction for Ki67 (Figure 2, B).

Diabetic group receiving (LC): showed positive reaction in the basal layer of the lingual oral mucosa (figure 2, C)

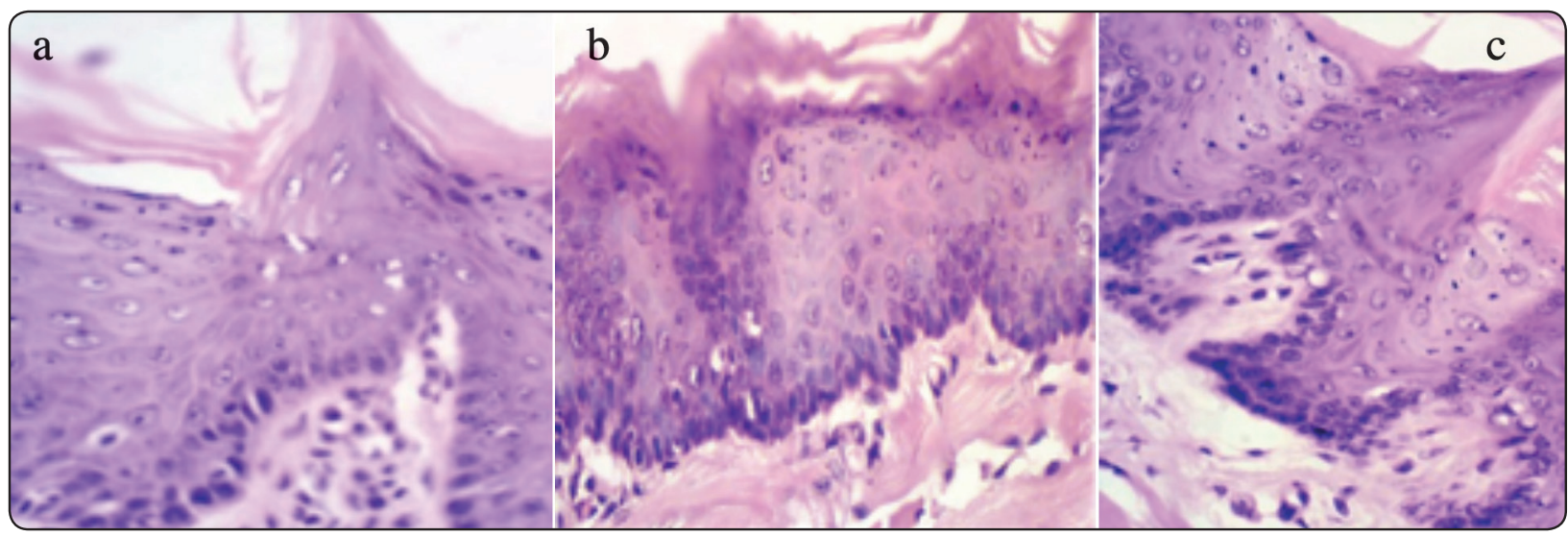

Fig. (1) Photomicrograph of the lingual mucosa. (a) control group showed stratified squamous epithelium with thin regular keratin layer. Well-formed connective tissue and muscle fibers running in different direction. (b) diabetic group showed flattening of the conical filliform papilla and hyperkeratosis. (c) diabetic receiving LC showed well formed filliform papillae and keratin layers (H\&E stain 400x).

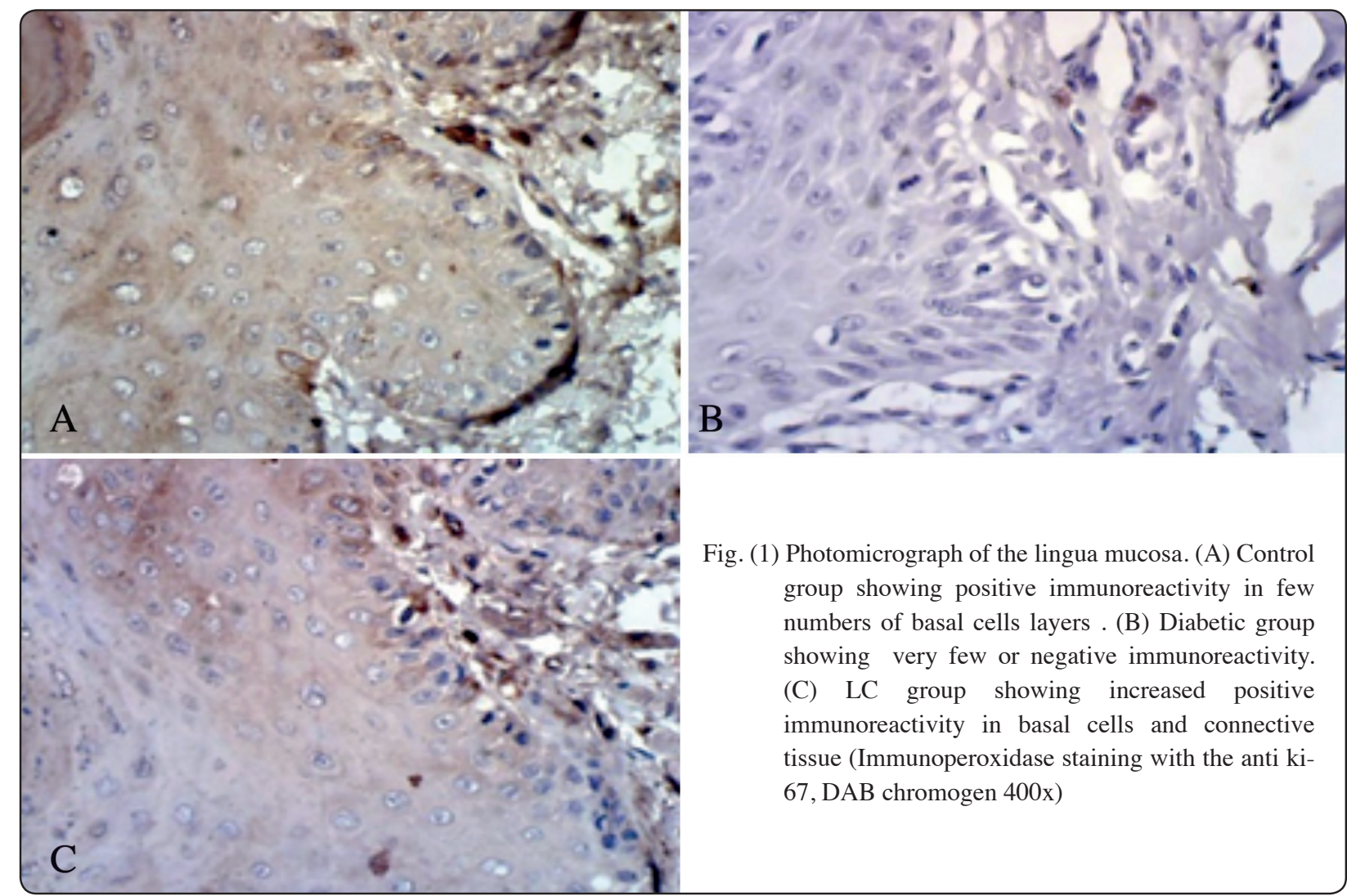




\section{Statistical Results}

STZ injection resulted in significant increase $(\mathrm{p}<0: 05)$ in all the biochemical parameters (serum glucose and serum insulin ratio). While (LC) administration resulted in significant decrease $(\mathrm{p}<0: 05)$ in serum glucose, serum insulin.

TABLE (1) Non fasting glucose serum levels $(\mathrm{mg} / \mathrm{dL})$ all over the period of the experiment in three groups of rats.

\begin{tabular}{cccccc} 
& $1^{\text {st }}$ week before STZ & 1 week after STZ & 2 week after STZ & 3week after STZ & 4 week after STZ \\
Control & $105.2 \pm 15.7$ & $104.4 \pm 14.7$ & $112.55 \pm 14.1$ & $110 \pm 15.2$ & $113.34 \pm 18.1$ \\
diabetic & $100.2 \pm 15.1$ & $416.8 \pm 27.3^{*}$ & $430.6 \pm 28.5^{*}$ & $422.8 \pm 23.6^{*}$ & $424.6 \pm 26.2^{*}$ \\
Carnitine & $111.3 \pm 16.3$ & $412.6 \pm 27.5^{*}$ & $280.2 \pm 13.5^{* \#}$ & $176 \pm 12.8 \#$ & $154.2 \pm 15.7^{\#}$ \\
\hline
\end{tabular}

All values have been expressed as Mean $\pm S D$. Control group $(C-v e ; n=10)$, diabetic group $(C+v e ; n=10)$, and carnitine $\operatorname{group}(n=10)$.

* Indicates significant differences from the value obtained in control negative group and \# indicates significant differences from the value obtained in control positive group at the level of $p<0: 05$.

TABLE (2) Non fasting insulin serum levels (pmol/L) all over the period of the experiment in three groups of rats.

\begin{tabular}{cccccc} 
& 1st weekbefore STZ & 1 week after STZ & 2 week after STZ & 3 week after STZ & 4 week after STZ \\
Control & $68 \pm 5$ & $68 \pm 6$ & $65 \pm 4$ & $66 \pm 6$ & $68 \pm 7$ \\
diabetic & $64 \pm 9$ & $165 \pm 18^{*}$ & $168 \pm 11^{*}$ & $170 \pm 7^{*}$ & $171 \pm 14^{*}$ \\
Carnitine & $65 \pm 7$ & $169 \pm 15^{*}$ & $125 \pm 15^{* \#}$ & $114 \pm 6 \#$ & $95 \pm 11^{\#}$ \\
\hline
\end{tabular}

All values have been expressed as Mean $\pm S D$. Control group $(C-v e ; n=10)$, diabetic group $(C+v e ; n=10)$, and carnitine group $(n=10)$. * indicates significant differences from the value obtained in control negative group and \# indicates significant differences from the value obtained in control positive group at the level of $p<0: 05$.

TABLE (3) Comparison between control, diabetic and control groups according to Ki67 immunostaining results:

\begin{tabular}{|c|c|c|c|}
\hline & Control & diabetic & LC \\
\hline Mean \pm SD & $0.067 \pm \mathbf{0 . 0 2}$ & $0.018 \pm \mathbf{0 . 0 1}$ & $0.062 \pm \mathbf{0 . 0 1}$ \\
\hline P1 & - & 0.000 & 0.000 \\
\hline
\end{tabular}

All values have been expressed as Mean \pm SD.P1 showed highly significant difference between control and diabetic group. $P 2$ showed highly significant difference between diabetic and LC group. 


\section{DISCUSSION}

There is no effective treatment to prevent the development or progression of human diabetic side effects. Therapeutic interventions that have been tried include optimal glycemic control and antioxidants ${ }^{29}$. (LC) is a conditionally essential nutrient that plays a vital role in energy production and fatty acid metabolism ${ }^{30}$.

In the present study, induction of diabetes altered the histological structure of the lingual oral mucosa, reflected atrophic changes in the lingual papillae of diabetic rats in the form of distorted filliform papillae with alteration in their normal inclination. That were in accordance with those who reported that after 4 weeks of diabetic induction, the tongue of diabetic rats revealed loss of the normal appearance of filliform papillae, most of them showed flattened with loss of their characteristic conical shape with evident hyperkeratosis, their epithelial lining showed marked thickening with many proliferating cells and ill-defined connective tissue papillae ${ }^{31}$.

Examination of the diabetic group revealed hyperkeratosis in the form increased thickness of keratin layer. In accordance with our results, Rodgers et al., who studied the expression of intracellular filaments, reported that keratin associated proteins and keratin complexes gene expression were increased in diabetic mice ${ }^{18}$.

Diabetes induces mitochondria morphological alternation, diminished oxidative phosphorylation. It leads to fatigue and exercise intolerance. Chronic and acute hyperglycemia, also, deteriorate the mitochondria's defense ability and increase free radicals. . Day by day, chronic complications will be developed ${ }^{32}$.

Histological examination of (LC) treated group revealed normal lingual mucosa. Our results are in accordance with the results of the previous studies that (LC) protects the cell membrane and DNA against the damage induced by free oxygen radicals ${ }^{33}$. Our results are in accordance with the results of the previous studies.
By statistical analysis, type 2 diabetes mellitus induce significant increase in serum glucose and insulin. While (LC) administration resulted in significant reduction in all these parameters. It was reported that (LC) plays a key role in the metabolism of FA by regulating its transport between the cytosol and mitochondria ${ }^{34}$.It also acts as a cofactor in betaoxidation by facilitating long chain FA entrance into mitochondria. In a clinical study by Muoio et al., they found that supplementation in a dose of (LC) $2 \mathrm{~g} /$ day orally for 6 month resulted in increased serum free (LC), decreased plasma glucose and insulin levels ${ }^{35}$.

Hyperglycaemia induced overproduction of superoxide by the mitochondrial electron transport chain appears to play a major role in the pathways leading to diabetic complications ${ }^{36}$. (LC) with various agents has been shown to prevent glucoseinduced activation of the diverse pathways implicated in diabetic complications ${ }^{37}$.

The Ki67 nuclear antigen, is expressed in all proliferating cells except those in the G0 stage ${ }^{38}$.Immunohistochemical examination of (LC) treated group revealed nosignificant difference in Ki67immunoreactivitycompared with control group. While diabetic group produced a significant decrease in Ki67 immunoreactivity indicating decreased cell proliferation. These findings were in agreement with Qiu $\mathbf{Z}$ et al., 2007 that high blood glucose hinders proliferation of cells ${ }^{39}$.

Also, another study on rats with chemically induced diabetes showed a reduction in cell proliferation 3-4 weeks after the reported onset of the diabetic state, but with noepithelial atrophy ${ }^{40}$. Jajaram et al., 2008 who found that nuclear changes in both buccal mucosa and tongue dorsum were significantly higher in diabetic group than control group. This could related to cellular age in patient with diabetes ${ }^{41}$. It was also explained that diabetes inhibited mitosis of the epithelial cells of the palate due to decrease in the number of S- phase cells ${ }^{42}$. And there was a decrease in the concentration of epidermal growth factor in saliva which might greatly affect the rate of cell division ${ }^{43}$. 
(LC) protects cell membrane and DNA against damage induced by free oxygen radicals and has a pivotal role in mitochondrial oxidation of longchain fatty acids which increase energy supply to the cell ${ }^{44}$. (LC) has free radical-scavenging activity and ability to scavenge superoxide anion and inhibit lipid peroxidation, thereby conferring protection against damage induced by hydrogen peroxide (H2O2) ${ }^{45-46}$.

This hypothesis was tested using mitochondrial targeting nutrients, including (LC) in a diabetic rat model. Reported that (LC) may be effective in improving immune function in type 2 diabetes through enhancement of mitochondrial function, decreased oxidative damage, and delayed cell death in the immune organs and blood ${ }^{19}$.

The histological results of the current work supplemented by the biochemical ones strongly recommend (LC) as an efficient protector against the detrimental effects of diabetes induced by streptozotocin on the lingual papillae most probably via its antioxidant effects.

\section{REFERENCES}

1. Sanjeeta N. Oral changes in Diabetes - a review. Journal of Dental and Medical Sciences. 2014; 13 (1): 36-39.

2. Sharma A, Tiwari A. Diabetes mellitus and Dental Disease-a review. JIDA. 2002; 73: 116-21.

3. Alvin C Powers. Diabetes Mellitus. In: Fauci AS, Braunwald E, Kasper DL, Hauser SL, Longo DL, Jameson JL, Loscalzo J, editors. Harrison's Principles of Internal Medicine. 17th Ed. United States of America: McGrawHill. 2008: 2275 - 304 .

4. Guggenheimer J, Moore PA, Rossie K, Myers D, Mongelluzzo MB, Block HM. Insulin-dependent diabetes mellitus and oral soft tissue pathologies. I. Prevalence and characteristics of non-candidal lesions. Oral Surg Oral Med Oral Pathol Oral RadiolEndod. 2000; 89 (5): 563 -69.

5. Finestone AJ, Bouriji. Diabetes mellitus in periodontal disease. Diabetes.1967:10: 336 - 40.

6. Cerda J. Periodontal disease in NIDDM. The effect of age and time since diagnosis. J Periodontol. 1995; 65: 991 -95.

7. Campus G, Salem A, Uzzau S, Baldoni E, Tonolo G. Diabetes and periodontal disease: A case control study. J Periodontol. 2005; 76 (3): 418 - 25.
8. Shlossman M, Knowler WC, Pettit DJ, Genco RJ. Type 2 DM and periodontal disease. JADA. 1990; 121: 532 - 36.

9. Vaz FM, Wanders RJ. Carnitine biosynthesis in mammals. Biochem. 2002; 361: 417-429.

10. Rebouche CJ. Carnitine function and requirements during the life cycle. FASEB J. 1992; 6: 3379-3386.

11. Fritz IB, Marquis NR. The role of acylcarnitine esters and carnitine palmityl transferase in the transport of fatty acyl group sacross mitochondrial membranes. Proc Natl Acad Sci U S A. 1965; 54: 1226-1233.

12. Rebouche CJ, Engel AG. Kinetic compartmental analysis of carnitine metabolism in the human carnitine deficiency syndromes. Evidence for alterations in tissue carnitine transport. J Clin Invest. 1984; 73: 857-867.

13. Rebouche CJ, Engel AG. Tissue distribution of carnitine biosynthetic enzymes in man. Biochim Biophys Acta. 1980; 630: 22-29.

14. Engel AG, Rebouche CJ. Carnitine metabolism and inborn errors. J Inherit Metab Dis. 1984; 7 (1): 38-43.

15. Brass EP. Pharmacokinetic considerations for the therapeutic useof carnitine in hemodialysis patients. Clin Ther. 1995; 17: 176-185, discussion 175.

16. Martinuzzi A, Vergani L, Rosa M, Angelini C. L-carnitine up take in differentiating human cultured muscle. Biochim Biophys Acta. 1991; 1095: 217-222.

17. Rebouche C. L-Carnitine, Acetyl-L-Carnitine, and Propionyl-L-Carnitine. In: Coates PM, Betz JM, Blackman MR, et al., eds. Encyclopedia of Dietary Supplements, 2nd Edition. 2nd ed. New York: Informa Healthcare. 2010:107-14.

18. Flanagan J L, Simmons P A, Vehige J , Willcox M DP, Garrett Qi. Role of L- Carnitine in diseases. Nutrition \& Metabolism. 2010; 16:7-30

19. Hao J, Shen W, Tian C, Liu Z, Ren J, Luo C, Long J, Sharman E, Liu J. Mitochondrial nutrients improve immune dysfunction in the type 2 diabetic Goto-Kakizaki rats. J Cell Mol Me. 2009; 13(4); 701-11.

20. Scholzen T and Gerdes J. The Ki-67 protein: from the known to the unkown. J Cell Physiol. 2000; 182: 311-22.

21. Heidebrecht HJ1, Buck F, Haas K, Wacker HH, Parwaresch R. Monoclonal antibodies Ki-S3 and Ki-S5 yield new data on the 'Ki-67' proteins.Cell Prolif. 1996 Jul;29(7):413-25.

22. Diop S1, Letestu R, Orsolani D, Leboeuf Y, Le Tutour P, Thiam D, Diakhate L, Valensi F. Expression of proliferation marker Ki 67 in chronic lymphocytic leukemia. Article in French Dakar Med. 2005; 50(2):65-8. 
23. Bubán T, Schmidt M, Broll R, Antal-Szalmás P, Duchrow M. Detection of mutations in the cDNA of the proliferation marker Ki-67 protein in four tumor cell lines. Cancer Genet Cytogenet. 2004; 149(1):81-4.

24. Alexandrakis MG, Passam FH, Kyriakou DS, Dambaki K, Niniraki M, Stathopoulos E.Ki-67 proliferation index: correlation with prognostic parameters and outcome in multiple myeloma. Am J Clin Oncol. 2004; 27(1):8-13.

25. Srinivasan K, Viswanad B, Asrat L, Kaul CL, Ramarao P. Combination of high-fat diet-fed and low-dose streptozotocin-treated rat: A model for type 2 diabetes and pharmacological screening. Pharmacol Res. 2005; 52:313-20.

26. .Barlagiannis D, Dietrich EM, Papaliagkas V, Makri S, Toskas A, Papamitsou T. Ultrastructural aspects of the effects of L-carnitine administration on epithelial cells in the aging rat tongue. HIPPOKRATIA 2014, 18, 1: 32-36.

27. Haroon S, Hashmi AA, Khurshid A, Kanpurwala MA, Mujuba S,Malik B, et al. Ki67 index breast cancer: correlation with otherprognostic markers and potential in Pakistani patients. Asian Pac J Cancer Prev. 2014;14: 4353---8.

28. Benevenuto TG1, Nonaka CF, Pinto LP, de Souza LB. Immunohistochemical comparative analysis of cell proliferation and angiogenic index in squamous cell carcinomas of the tongue between young and older patients. Appl Immunohistochem Mol Morphol. 2012; 20(3):291-7.

29. Filippi, A. "Ozone is the most effective disinfectant fordental treatment units: results after 8 years of comparison”, Ozone Sci Eng. 1997;19:527.

30. Ziegler D, Hanefeld M, Ruhnau KJ et al. Treatment of symptomatic diabetic peripheral neuropathy with the antioxidant alpha-lipoic acid. Diabetologia. 1995:38: 1425 .

31. Al-Khalifa A1, Mathew TC,Al-Zaid NS, Mathew E, Dashti HM. Therapeutic role of low-carbohydrate ketogenic diet in diabetes Nutrition. 2009; 25(11-12):1177-85.

32. Rodgers KE, Ellefson DD, Espinoza T, Hsu YH, diZerega GS, Mehrian-Shai R. Expression of intracellular filament, collagen, and collagenase genes in diabetic and normal skin after injury. Wound Repair Regen. 2006 ;14(3): 298305.

33. Sreekumar R1, Nair KS.Skeletal muscle mitochondrial dysfunction \& diabetes. Indian J Med Res . 2007;125, 399-410.

34. Su S L, Kuo C L , Liu C S. Diabetes and Mitochondria The Changhua Journal of Medicine. 2013; 11, 1-7.
35. Wang C, Sadovova N, Ali HK, Duhart HM, Fu X, Zou X. L-carnitine protects neurons from 1-methyl-4phenylpyridinium-induced neuronal apoptosis in rat forebrain culture. Neuroscience 2007; 144:46-55.

36. Xia1Y, Li Q, Zhong W, Dong J, Wang Z and Wang C. L-carnitine ameliorated fatty liver in high-calorie diet/STZinduced type 2 diabetic mice by improving mitochondrial function. Diabetology\& Metabolic Syndrome. 2011; 3:31.

37. Muoio DM, Noland RC, Kovalik JP. Muscle-specific deletion of carnitine acetyl transferase compromises glucose tolerance and metabolic flexibility. Cell Metab. 2012;15: 764-777.

38. Petersen KF, Dufour S, Befroy D, Garcia R, Shulman GI. Impaired mitochondrial activity in the insulin-resistant offspring of patients with type 2 diabetes. N Engl J Med. 2004; 350: 664-71.

39. Qiu Z, Kwon Ah, Kamiyama Y. Effects of Plasma Fibronectin on the Healing of Full-Thickness Skin Wounds in Streptozotocin-Induced Diabetic Rats. J Surg Res. 2007; 138, 64-70.

40. Nishikawa T, Edelstein D, Du XL, Yamagishi S, MatsumuraT, Kaneda Y. Normalizing mitochondrial superoxide production blocks three pathways of hyperglycaemic damage. Nature. 2000; 404 : 787-90.

41. Jajarm HH1, Mohtasham N,Moshaverinia M, Rangiani A . Evaluation of oral mucosa epithelium in type II diabetic patients by an exfoliative cytology method J Oral Sci. 2008;50(3):335-40.

42. Gerdes J, Li L, Schlueter C, Duchrow M, Wohlenberg C, Gerlach C. Immunobiochemical and molecular biologic characterization of the cell proliferation-associated nuclear antigen that is defined by monoclonal antibody Ki67. American Journal of Pathology. 1991; 138: 867-873.

43. Hamilton AI, Blackwood HJJ Insulin deficiency and cell proliferation in oral mucosal epithelium of the rat. J.Anat. 1977; 124: 757-763.

44. Nagy A, Nagashima H, Cha S, Oxford GE, Zelles PeckAB, Humphrays-Beher MG Reduced oral wound healing in the NOD mouse model for type I autoimmune diabetes and its reversal by epidermal growth factor supplementation. Diabetes. 2000; 50 (9): 2100-4.

45. Zhou X, Liu F, Zhai S. Effect of L-carnitine and/ or L-acetyl-carnitine in nutrition treatment for male infertility: a systematic review. Asia Pac J Clin Nutr. 2007;16:383-90.

46. Panneerselvam KS, Kumaran S. L-Carnitine and alphalipoic acid improves mitochondrial function during ageing process. Clin Nutr. 2006 May 11. 